\title{
Zero-Base Budgeting in Historical and Political Context: Institutionalizing An Old Proposal
}

\author{
F. TED HEBERT \\ The University of Oklahoma
}

The much heralded zero-base budgeting system, a matter of interest to public administrators and politicians alike, is certainly not a new idea to students of government budgeting. Its history reaches back almost as far as the history of American executive budgeting itself. Writing in 1924, just three years after passage of the Budget and Accounting Act, E. Hilton Young and N. E. Young describe the start of a British budget cycle as follows:

On October 1st [the Treasury] sends a circular letter to the officers responsible for the preparation of the estimates in each civil de. partment, requesting them to prepare estimates of the departments in the coming year. There are two stereotyped admonitions in this circular: one is general, that the state of the public revenue demands the utmost economy; the other is a particular warning against assuming last year's estimates as the starting point for those of the next. The latter is a necessary warning. It must always be a temptafion to one drawing up an estimate to save himself trouble by taking last year's estimate for granted, adding something to any item for which an increased expenditure is foreseen. Nothing could be easier, or more wasteful and extravagant. It is in that way that obsolete expenditure is enabled to make its appearance year after year in the estimates, long after all reason for it has ceased to be. By this warning and by the general admonition as to the need for economy the departments are no doubt duly impressed. ${ }^{1}$

In a ten year later examination of the budgetary systems of the United States and of other nations, A. E. Buck quotes the Youngs with apparent sympathy ${ }^{2}$ and asks:

... do current or past requirements have any value in [expenditure estimations]? Undoubtedly so; they are facts which should be regarded as elements in the calculation, although they should not be

F. Ted Hebert is Associate Professor of Political Science and Assistant Dean of the Graduate College at The University of Oklahoma. He received his B. A. from Louisiana Tech and his M. A. and Ph. D. from The University of lowa. He has been employed by Public Affairs Research Council of Louisiana, the Louisiana state budget office, and since 1969, on the faculty of Oklahoma.

An earlier version of this paper was presented at the Central States Conference on Public Administration, Kansas City, Missouri, November 19.20, 1976.

1E. Hilton Young and N. E. Young, The System of National Finance, 2nd edition (London: John Murray, 1924), pp. 23-24. Emphasis added.

2A. E. Buck, The Budget in Governments of Today (New York: The MacMillan Company, 1934), pp. 171-172. 
accepted as inevitably indicative of future needs and the necessity for a sustained level of expenditure. ${ }^{3}$

Although not using the terms "zero-base budgeting" (ZBB), these early authors were calling attention to the very same concern that has captured the interest of budgetary system reformers today.

\section{ZERO-BASE BUDGETING TODAY}

Before undertaking further efforts to trace historical roots of ZBB it is useful to attempt a description of the recent reforms initiated under that rubric. Doing so requires examination of efforts made in several state and local jurisdictions.

The place with which to begin is the State of Georgia. Here Governor Carter undertook to implement ZBB with the help of Peter A. Pyhrr whose 1970 article in Harvard Business Review is generally credited with sparking the flames of renewed interest in the approach. ${ }^{4}$ The objective sought by the ZBB effort is well stated by George Minmier in his evaluation of Georgia's experience: "Zero-base budgeting is a technique whereby the total cost of every item included in the proposed budget must be justified and approved." This means that items carried forward from previous years are subject to review just as are new recommendations. This understanding of ZBB accords well with the desires of the Youngs and of Buck quoted above, and with a 1969 statement of Arthur F. Burns, now Chairman of the Federal Reserve Board, when he said: "Substantial savings could undoubtedly be realized if [it were required that] every agency . . . make a case for its entire appropriation request each year, just as if its program or programs were entirely new." ${ }^{16}$ Pyhrr began his 1970 article with that quotation, clearly indicating that such was the goal of ZBB as he conceived it.

What remains is to see how the Georgia budgetary system was reformed to achieve that goal. Of prime importance was a requirement that all concerned with the budgetary process begin to focus their attention upon the activities performed by state agencies, to "identify the current year's activities and operations. ${ }^{17}$ The costs of the activities were to be carefully

\footnotetext{
3/bid., p. 175.

4Peter A. Pyhrr, "Zero-Base Budgeting," 48 Horvard Business Review (NovemberDecember, 1970), pp. $111-121$.

5George Samuel Minmier, An Evaluation of the Zero-Base Budgeting System in Governmental Institutions (Atlanta: Georgia State University School of Business Administration, 1975), p. 10.

6Quoted in Pyhrr, "Zero Base Budgeting," p. 111, from a speech delivered by Mr. Burns at the Plaza Hotel, New York, December 2, 1969.

7Peter A. Pyhrr, Zero Base Budgeting: A Practical Management Tool for Evaluating Expenses (New York: John Wiley, 1973), p. 12.
} 
calculated, a procedure which may be new in some governmental units accustomed to focusing upon objects of expenditure only. Frequently, though, the activities corresponded with the lowest organizational level within an agency and cost may thus equal its budget.

The second step which the procedure requires is the formulation of decision packages identified with each activity. These are of four types:

1. A "business as usual" package, supporting both the present means of performing the activity and the present performance level.

2. A "different level" package considering an increase or decrease in the performance and funding level of the activity.

3. An "alternative means" package suggesting a different approach to the task which the present activity is designed to perform.

4. A "new activity" package. This would relate only tangentially, if at all, to present activities.

Each organizational unit is expected to develop one or more such decision packages for each activity under its responsibility. Pyhrr suggests that one package should indicate a "minimum level of effort" - the basic amount of funds and number of employees necessary to keep the activity functioning, even though failing to meet goals or solve problems for which it is intended. Additional packages would suggest alternative means or levels which, added to the minimum level package, would move toward goal attainment. Each organizational unit, after preparing a justification for each package, is required to rank its packages from the one most desired, that which should be funded even in event of the most severe financial constraint, to that least required, which should be eliminated first if funding levels are not sufficient.

Although Pyhrr stresses the importance of cost/benefit analysis as a basis for ranking, he makes few references to any effort to determine the goals of activities or to measure goal accomplishment. ${ }^{8}$ This possible shortcoming will be returned to below.

Once an individual unit has ranked its own packages, these are forwarded to the next higher organizational level where rankings from various sub-units are consolidated into a department-wide ranking. Finally, these departmental rankings are submitted to the executive budget office for consideration. Matters can become highly complex, with thousands of individual decision packages. ${ }^{9}$ Various efforts at simplification have been undertaken including the establishment of a cutoff at, for example, $60 \%$

\footnotetext{
8lbid., pp. $62-70$.

9 lbid., p. 64.
} 
of the current budget. There is then no need to review those packages which fall below that level, and efforts can concentrate on ranking only those which move to higher funding levels. ${ }^{10}$ For the 1978 fiscal year, agencies are instructed to prepare packages at these levels: minimum objective level (something below current funding); current objective level (service the same with costs usually somewhat higher); and improvement objective level (service closer to achieving activity goals). Departments then will rank these packages. Some activities may find their improvement objective level packages ranked above the current objective level packages of other activities. Minmier indicates that in recent years no effort has been made to prepare a ranking at an organizational level higher than the department. ${ }^{11}$

To support the rankings, various forms for data presentation have been developed in Georgia and in other jurisdictions attempting ZBB. ${ }^{12}$ Although there are obvious differences among these (even within the Georgia system from year to year), there are significant similarities. One is the inclusion of a statement of purpose of the activity. This allows for a brief narrative description of the goal(s) of the activity. There is a similar space for a narrative description of the activity itself which is then elaborated upon by a quantitative presentation of workload data, typically for three fiscal years. Another important feature of the presentation is a statement of the consequences which would result from failure to approve the package - the impact that such failure would have upon goal achievement. This is accompanied by a brief statement of alternatives which are usually the subjects of other decision packages. Consequently, from the forms supporting any one decision package the reviewer can get a superficial look at the total consideration given to that activity. Finally, the forms include specific financial and personnel requests. ${ }^{13}$

Although this comment is probably more severe than evidence presented so far justifies, the zero-base budgeting efforts being made today probably do not deserve to be labeled "zero-base budgeting." Pyhrr's sympathetic description of the Georgia system, as well as Minmier's more critical examination, leave doubt that any real effort was made to justify and approve in total every item in the budget. This is not to say that the reforms may not be important, a matter to be addressed below, but to

10/bid., pp. 83-86.

11 Minmier, op. cit., p. 105.

12Among the ZBB forms examined were those of Georgia, included in Pyhrr, op. cit., and in Minmier; those of Wilmington, Delaware, and Garland, Texas.

13Although this description of ZBB is based heavily upon the Georgia experience, it captures the fundamental features of reforms being promoted generally. 
argue that all activities or programs are considered from zero, that new proposals have the same chance to be funded (given equal merit) as old programs is not justified.

What, then, is ZBB all about? If it is not simply a "justify from zero" effort, what is it? This can best be answered by seeing how it fits into the development of public budgeting in the United States.

\section{ZERO-BASE BUDGETING IN HISTORICAL CONTEXT}

\section{ZBB: A Secondary Goal of Earlier Reforms}

The most complete presentation of earlier reform efforts is found in Allen Schick's excellent article, "The Road to PPB," published in 1966.14 Schick maintained that we have seen the emphasis of reform placed, successively, upon the confrol, management, and planning purposes of budgeting. ${ }^{15}$ Each of these foci was accompanied by a particular budgetary scheme, object classification budgeting, performance budgeting, and the planning programming budgeting system, respectively. How orderly matters would be if one could identify a fourth purpose which the budgetary process might serve and then proceed to identify ZBB with that purpose. Such is not the case, however. As shown above, the demand that budget makers justify from zero reaches back well into the "control oriented" period. It was not totally overlooked during either the "management" or the "planning" periods. The thrust of the Hoover Commission recommendation, which was the capstone of performance emphasis, clearly encompassed an effort to justify from zero. The following recommendation from the Commission is not very different from a portion of the Georgia budget process.

Supporting [budgetary] detail submitted initially would include a narrative explanation of the significance and scope of each subprogram - by actiivty or subunit when appropriate - changes in emphasis over previous years, together with a progress report of work accomplished or under way. Additional data would be set forth in tabular form showing comparative work load, unit costs, and such other yardsticks as might be necessary to evaluate any elements of the appropriation request. ${ }^{16}$

Later, as the focus of reform shited to planning, concern for justification from zero persisted. The most noteworthy effort to implement a zero-base

14Allen Schick, "The Road to PPB: The Stages of Budgetary Reform," 26 Public Administration Review (December, 1966), pp. 243-258.

15 /bid., pp. 244-45.

16Commission on Organization of the Executive Branch of Government, "Budgeting and Accounting" (Washington, D.C.: Government Printing Office, 1949), p. 78. Emphasis added. 
budget process was undertaken by the Department of Agriculture in preparation of the 1964 budget. Wildavsky and Hammarn have provided an excellent description and evaluation of this exercise. ${ }^{17}$ In the USDA budget preparation instructions, sub-units were told that "All programs will be reviewed from the ground up and not merely in terms of changes proposed for the budget year. ${ }^{18}$ This was followed by an effort (not altogether successful, according to Wildavsky and Hammann) to use these justifications as a basis for allocating resources.

Still later, the planning programming budgeting system which was introduced throughout most of the federal government in 1965 clearly demanded that budget preparation include consideration of the contribution which each program (or program component) made to accomplishment of a specific end or objective. ${ }^{19}$ PPB, as implemented by the federal government, required that agencies prepare Program Memoranda which provided a justification for the program in terms of its contribution to a stated objective. As with ZBB, agencies were told to "Compare the effectiveness and the cost . . . of alternative types of programs designed to meet the same or comparable objectives, and of different levels within a given program category." ${ }^{\prime 20}$ These alternatives were to be compared with present programs for which, of course, complete cost and benefit data would be needed. Clearly this process required examining total costs and benefits of current programs, an examination from a zero base. A later instruction told federal agencies that Program Memoranda should "be prepared with as much attention paid to reducing and modifying obsolete and low priority programs as expanding others and introducing new ones. ${ }^{21}$

The desire to achieve zero-base budgeting, then, has been a motivating force behind most of the budget reform efforts of the twentieth century.

17Aaron Wildarsky and Arthur Hammond, "Comprehensive Versus Incremental Budgeting in the Department of Agriculture," 10 Administrative Science Quarterly (December, 1965), pp. 321-346. The correct spelling of the second author's name is Hammann, but was spelled incorrectly in the original publication.

18 /bid., p. 326.

19See Melvin Anshen, "The Federal Budget as an Instrument for Management and Analysis," in David Novick, ed., Program Budgeting: Program Analysis and the Federal Budget (Cambridge: Harvard University Press, 1967), pp. 3-23. See also other selections in this excellent volume on PPB.

20 Executive Office of the President, Bureau of the Budget, "Bulletin No. 66-3" (October 12, 1965), as reprinted in Fremont J. Lyden and Ernest G. Miller, Planning Programming Budgeting: A Systems Approach to Management (Chicago, Ill.: Markham Publishing Company, 1968), p. 413. Emphasis added.

21Executive Office of the President, Bureau of the Budget, "Supplement to Bulletin No. 66-3" (February 21, 1966), as reprinted in Lyden and Miller, op. cit., p. 422. 
As Schick correctly indicates, budgets are expected to serve multiple purposes. ${ }^{22}$ The desire to review ongoing programs from zero, to thereby curtail or eliminate outdated or non-productive programs, is one of those purposes, and it has persisted as an objective of governmental budgeting throughout all the decades of reform. The present ZBB effort is its latest manifestation and gives it greater emphasis than ever before. Yet, it remains to be seen whether the current effort can succeed where others have failed, whether the ZBB scheme as introduced in Georgia is sufficiently different from earlier reforms to make such success even likely.

\section{The Georgia System and Earlier Reforms}

To judge the potential for success of the current ZBB effort, one must see just how it relates to previous reforms. The brief presentation of the Georgia scheme given above provides insufficient information for such an examination, but a slightly more detailed look at certain features will facilitate fitting this latest effort into the historical pattern of reform. (While comments here refer specifically to Georgia, they apply equally to other ZBB efforts that follow Pyhrr's design.)

A first question to ask is whether ZBB is an extension of the planning programming budgeting movement. If it were, a significant feature of it should be heavy emphasis upon the stating of a concrete objective, the attainment of which is measurable. It was this specification of objectives, and the formal presentation of the relationships between program activities and attainment of those objectives, which characterized PPB. A look at Pyhrr's deseription and Minmier's evaluation of the Georgia system, as well as at other ZBB efforts, reveals little emphasis upon the ultimate ends which government programs are designed to serve. Pyhrr devotes one chapter of his book to specifying the inadequacies of PPB and to showing that ZBB is capable of filling certain gaps therein. Fundamental to his criticism is a contention that PPB is designed for long-range planning and provides little help with short-term decisions, that PPB "focuses on the effect that a group of activities has in achieving certain objectives rather than the efficiency in which each activity is carried out," and that PPB focuses primarily upon new programs or program changes rather than on current programs. ${ }^{23}$

Certainly Pyhrr is correct. Zero-base budgeting and planning programming budgeting are quite distinct systems. Although Pyhrr in several places stresses the requirement that a ZBB process focus attention upon the

22Allen Schick, Budget Innovation in the States (Washington, D. C.: The Brookings Institution, 1971), pp. 1-13.

23Pyhrr, op. cit., p. 150. 
benefits of activities, there is little in the Georgia process which facilitates this. For example, he says that in constructing decision packages, managers should stress those things which the program accomplishes, being interested in the "benefits achieved for a given expenditure." 24 Elsewhere he says that each decision package should, at a minimum, provide a cost/benefit analysis - clearly a focus on program objectives. ${ }^{25}$ However, an examina. tion of the Georgia budget forms (and, for that matter, forms used in other ZBB systems) reveals little emphasis on previous statement of objectives or presentation of cost/benefit analyses. Drawing from an example Pyhrr presents, a decision package of the Highway Patrol-Field Operation includes the following Statement of Purpose:

To patrol the rural and public roads and highways throughout the State, to prevent, detect and investigate criminal acts, and to arrest and apprehend those charged with criminal offenses appertaining thereto, and to safeguard the lives and property of the public. ${ }^{26}$

A package of the Air Quality Laboratory presents the following:

Ambient air laboratory analysis must be conducted for identification and evaluation of pollutants by type and by volume. Sample analysis enables engineers to determine effect of control and permits use of an emergency warning system. ${ }^{27}$

Neither of these statements even approaches the degree of precision necessary for a cost/benefit study nor provides higher level decision makers with a clear understanding of the contribution which the activity makes to a higher purpose. Even granting that other sections of the form, especially one headed "Consequences of Not Approving Package," supply some supplementary information, there is still a vast gap between what is provided and what would be necessary for a precise (quantitative or non-quantitative) evaluation of the package.

Since Pyhrr has made clear his dissatisfaction with the planning programming budgeting reform, it is perhaps unfair to evaluate his ZBB proposal against the criteria for implementation of PPB - especially since few, if any, PPB efforts met those criteria. One simply needs to discount Pyhrr's suggestions that ZBB would permit cost/benefit analysis or really focus attention upon program accomplishments.

If ZBB is not an extension of the PPB reform, what might it be? One possibilty is that it is a revival of the earlier marginally successful reform

24/bid., p. 51.

25 lbid., p. 62.

26 Ibid., p. 42.

27 /bid., p. 66. 
effort generally known as "performance budgeting." This, of course, is the reform Schick associated with a management emphasis in budgeting and which was promoted by the Hoover Commissions. Under these proposals there was an effort to lessen the rigidity of control by the executive budget office and the legislature. Administrators of programs were to gain latitude to take steps which, it was hoped, would produce greater efficiency. The desire for efficiency was the driving force behind the performance budgeting movement. ${ }^{28}$

To encourage efficiency, budget makers were required to focus attention upon the activities of their organizations rather than upon the traditional inputs represented by line items. In the words of Jesse Burkhead, "Performance classification provides the link between the things bought and the things done or accomplished." 29 ge goes on to give examples of "things done," to include roads built, tons of food transported, acres of trees planted, tax returns audited or pennies minted. ${ }^{30}$ Each of these may be seen as an end product of a government activity.

The next step in performance budgeting was to attach costs to each of these activities, determining appropriate unit costs. It is here that many performance budgeting schemes broke down. To establish the full unit cost required a more elaborate accounting system than most agencies or governments had; it required an ability to assign overhead as well as direct costs to performance units.

Despite this difficulty, many governments in the United States implemented a performance budgeting system, at least in name. A look at the Budget of the United States today reveals the inclusion of activity measures. In many cases, though, these innovations were but an overlay upon the older budgetary process. This author's experience in the State of Lovisiana may be indicative of widespread practice.

The Lovisiana Budget Office in 1965 was employing, in part, a performance budget. Agencies were required to submit, on the first page of their budget requests, a statement of purpose and measures of their activities. Frequently, the statement of purpose provided was merely a quotation from the statutory authority of the agency. Activity measures were of the crudest sort and were supplied only by those agencies which had activities readily quantifiable. Even more significant is the fact that when the budget request forms reached the budget office, this author received the

28For a discussion of performance budgeting, see Schick, op. cit., pp. 44-85.

39 Jesse Burkhead, Government Budgeting (New York: John Wiley and Sons, Inc., 1956), p. 140.

30/bid., p. 142. 
first page (containing the performance information) while the responsible budget examiner received the request presented in an object classification. All decision making from that point on was done through examination of the object requests. Not until time to print the budget was the performance information (edited to take up $1 / 2$ page) turned over to a secretary for typing along with the governor's recommendation - presented in an object classification.

Schick's description of the "hybridization" of performance budgeting in many states accords well with that found in the Lovisiana budget system. There are reasons, then, for severe reservations about "classification by activities" having had any large impact on state or federal budgeting.

As was indicated above, the data employed in ZBB seem to provide little information about objectives or ends, or the accomplishment of those objectives. As examples, information required by both the Georgia and the Garland, Texas, forms is workload information quite similar to that demanded by performance budgeting. Further, the brief narrative "statements of purpose" are quite like the statements which accompanied Lovisiana's performance forms. As an example of activity measures, the Garland instruction Manual for 1976-77 provides a completed form for a Fleet Maintenance Center, General Office. ${ }^{31}$ Workload data are provided for the following:

\section{Work Orders Processed Mainstem Report Terms Parts Orders Processed Parts Issue Transactions}

In each case, work unit data are provided for three years.

The Georgia forms have sought to have agencies go one step further, if possible, and calculate unit cost data and man hour data in relation to the workload statistics. In both cases, the similarity to the requirements of performance budgeting schemes is most marked. Even the weaknesses are similar. Both Pyhrr and Minmier decry the lack of adequate cost information which is applicable at the activity level. ${ }^{32}$

This focus upon workload data and upon brief descriptions of the purposes of activities is so strikingly similar to the performance budgeting reform that it cannot be overlooked. In both cases there is, it appears, an assumption that the budgetary process has little to do with the selection of the objectives of government programs. For both, budgeting is primarily a

31 Budget Office, City of Garland, Annual Budget Instruction Manual, 1976-77 (Garland, Texas: City of Garland, n.d.), p. 23.

32Pyhrr, op. cit., p. 132, and Minmier, op. cit., p. $101 \mathrm{ff}$. 
process through which an attempt is made to assure that those goals which are sought are pursued in the most efficient manner. It seems that ZBB may be a bit more open to consideration of alternative activities for pursuit of given goals than some formulations of performance budgeting may have been, but a basic similarity remains. It is the activity which is important to budget makers and the efficiency with which that activity is carried out.

Despite this obvious similarity, there is a distinction which must be noted. This distinction could be, if ZBB were to be fully implemented (and implemented differently from the way it seems to have been so far), more important than the similarities. It is the feature which proponents of ZBB talk about most, that budget makers must justify their activities from zero. Although other reforms have included this demand, none has given it much emphasis. As best can be told so far, neither does ZBB. The formal requirements, the forms, and the results do not indicate any truly concerted effort to justify activities from zero, let alone every activity every year. ${ }^{33}$

If ZBB does not really promote justification from zero and seems to have some of the same weaknesses as performance budgeting, is there anything about it which might justify the attention it is receiving? One possibility is the fact that ZBB has revived interest in an approach to budgeting which was suggested in 1952 by Verne B. Lewis and labeled the "alternative budget system." 34 Lewis explicitly declined to suggest the mechanism through which his approach to budgeting might be implemented but did describe the system's major features. Each preparer of a budget would be required to consider the services which could be provided at, perhaps, five different funding levels. These levels might be varied to take account of particular situations, but would adhere to the general pattern. At each level the "nature, quantity, and quality of services" which the agency could provide would be specified. ${ }^{35}$ Each higher administrative level would have opportunity to review the alternatives. The highest levels, and even the legislature, would have access to a group of alternatives. ${ }^{36}$

A slight variation of the alternative budget scheme was suggested in 1971 by Merewitz and Sosnick. They proposed that three. levels of funding might be sufficient. These levels would provide, in comparison to the present year, "the same-dollar amount," "the same-prformance amount," and "the

33On the impact of ZBB upon budgets see Minmier, op. cit., pp. 118 ff and 154 .

${ }^{34}$ Verne B. Lewis, "Toward a Theory of Budgeting," 12 Public Administration Review (Winter, 1952), pp. 42-54.

35 /bid., p. 49.

36/bid., pp. 53-54. 
recommended amount."3i Justifications, including quantitative supporting data if available, would be provided for the recommended amount and to support conclusions regarding the impact which would result from funding at the alternative levels. Higher administrative units would consolidate these reports into alternatives similarly defined, but covering the entire higher level agency. Additionally, the higher level request would indicate the distribution of funds which would be made to subordinate agencies. For example, if the department received the same-performance amount, some of the lower agencies might get as much as or more than their recommended amounts while others could get less than their same-dollar amounts. The process would compel budget reviewers to consider such trade-offs. ${ }^{38}$ Merewitz and Sosnick comment:

The alternative budget approach ... has important advantages over zero-base budgeting. Both procedures encourage officials to consider curtailing or terminating ineffective or obsolete programs. The alternative budget approach, however, does not throw away information about last year's appropriation and does not demand justifications that cannot be given. It recognizes that what is the best allocation of funds is a matter of judgment, and it seeks to provide decision-makers with the information needed to pass judgment. This information consists of a description of what would be gained in one program and lost in another if funds were reallocated. ${ }^{39}$

This descripiton of the alternative budget system does not differ markedly in some of its features from the ZBB system as proposed by Pyhrr. In fact, the ZBB procedures implemented in Georgia and elsewhere can be seen as an effort to institutionalize an alternative budget system in combination with important features of performance budgeting. Admittedly, the focusing of attention at the activity level (perhaps lower than Lewis or Merewitz and Sosnick had in mind) is an important variation of alternative budgeting. However, doing so ties this recent reform more closely to the performance budget approach. It is at the activity level that there are likely to be countable work units to which costs can be attached. Decisions under the ZBB system are apparently to be made in terms of the impact which various funding levels, represented by the decision packages, have upon performance of the activities and, especially, upon the accomplishment of units of work.

\footnotetext{
37Leonard Merewitz and Stephen H. Sosnick, The Budget's New Clothes: A Critique of Planning-Programming-Budgeting and Benefit-Cost Analysis (Chicago: Markham Publishing Company, 1971), p. 66.

:38/bid., pp. 68 and 69.

39lbid., p. 70.
} 
What is new in ZBB is not the goal or focus of budgeting but rather it is the concerted effort to institutionalize earlier reform proposals. By requiring the presentation of performance information and by requiring the preparation of decision packages which are comparable to alternatives, ZBB establishes procedures which compel decision makers to consider issues and data frequently overlooked. The ranking process, even if not adhered to rigidly, at least focuses attention upon possible effects which funding decisions may have. The effects are not, however, stated precisely in terms of achieving objectives. Compared to an ideal of PPB, the ZBB system stops far short of addressing the attainment of objectives. It does facilitate consideration of the efficient conduct of activities and of a possible trade-off between one activity and another.

As with efforts to implement performance budgeting, the accumulation of cost and activity data is limited. Although Pyhrr gives assurance that, once in place, the ZBB system should not add significantly to time and money costs of budgeting, there can be little doubt that assembling the data required for full implementation would be costly indeed.

In addition to these money costs, there are important political costs of ZBB implementation. These can be suggested by examining the political history of the earlier reforms which ZBB seems to encompass. In addition to fitting into an historical context, the emergence of ZBB at this particular time - after its having been around for at least 50 years - is of political significance.

\section{ZERO-BASE BUDGETING IN POLITICAL CONTEXT}

No examination of political considerations associated with budgetary reform would be complete without reference to the work of Aaron Wildavsky. ${ }^{40} \mathrm{His}$ description of the politics of the budgetary process provides the base from which to begin a discussion of reform proposals. That description unabashedly admitted that public budgeting is a political matter and, further, Wildavsky judged that it ought to be political. He recognized that the budgetary process itself, as well as the decisional outputs of that process, are influenced by partisan considerations, by interest groups and by strategies devised by participants and, further, that the process and outputs should be so influenced. ${ }^{41}$

Any attempt to reform the process will succeed or fail, in part, on the basis of how well its proponents recognize the political forces at work

40Aaron Wildavsky, The Politics of the Budgetary Process, Ist edition (Boston: Little, Brown and Company, 1964).

41 Mention should be made of one earlier work which did show sensitivity to political considerations, that of Burkhead cited above. 
and design the reform to gain sufficient support. One of the difficulties with which the current ZBB reforms must contend is the still present negative reaction to the earlier PPB reform effort. As a means of considering the effect of this as well as other political matters, it is helpful to look at the politics of earlier reforms.

According to Schick, the performance budgeting movement which caught on after World War II was really an extension of pre-war developments. Attention had been diverted by the war, but at its close energies could be used to implement reforms which had been discussed by students of public administration during the 1930s. Of special importance was the focus upon work units which grew quite naturally from the scientific management movement. ${ }^{42}$ This concern, coupled with the post-war desire to assure efficiency in public spending (a matter of little interest during the war years), combined to produce a receptive political environment for performance budgeting. This environment was at least hospitable for a discussion of performance budgeting. It may have been less hospitable for its actual implementation.

Schick points out that there was no real urgency to budgeting reform in the early 1950s; neither the general public nor public administrators felt there was a crisis that might be resolved through changes in budgetary procedures. There was a general concern over rising government spending but that did not necessarily suggest sweeping changes in budgetary practices. ${ }^{43}$ Neither executives nor legislatures stood to enhance their political strengths through adoption of performance budgeting. Neither would gain markedly, as the executive may have gained with adoption of the executive budget system thirty years earlier. ${ }^{44}$ This time many participants simply did not see the value in institutionalization of the reforms. Obviously, if one set of participants (the legislature, for example) had decided that there was much to gain, there would have been a willingness to commit political capital, to engage in a struggle to insure true implementation and thus reap the benefits. This did not occur. Implementations were partial, at best, and were usually simple overlays upon traditional budgeting. The traditional pattern of bargaining over incremental changes in line-items remained the major pattern.

In describing the political considerations which may have influenced the adoption or rejection of PPB, Schick explains the benefits which various participants gain from preservation of the traditional process. With regard

\footnotetext{
42 Schick, op. cit., pp. 30-31.

43/bid., p. 63-64.

44 /bid., p. 64.
} 
to the preparers of budgets, the spending agencies, Schick notes that the proposed reforms would have inhibited the agencies' abilities to "sell" their programs. The agencies generally prefer a subjective evaluation process within which they can make use of interest group and clientele support as defenses of funding. With line-item budgeting, agencies find it easier to manipulate the facts to their advantage.$^{+5}$ Lest one immediately react negatively to such an explanation for the rejection of budget reform, note that Wildarsky defends such subjective techniques as both simplifying devices and as means of assuring input of various political interests. Frequently, matters to be decided are of such great complexity that a reviewer will not have the technical expertise to make a decision based on a presentation of material which seeks to justify a total program. He or she simply will not be able to comprehend and to consider all implications of major program changes.

In defending incremental decision making as a means of furthering representation, Wildavsky treats favorably a partial-view-of-the-public-interest in which, through the budgetary process, various participants contend heatedly, each defending their own interests, with no one participant trying to take into consideration the interests of all groups in society. No preparer of a program and no reviewer is required to think of himself or herself as speaking for some vague public will. The competition and struggle engendered by each agency and each interest group seeking its own advantages are seen as appropriate. ${ }^{46}$

Earlier reforms did not dramatically alter the general nature of budgetary politics. With regard to central budget offices, Schick notes that their prime responsibility is budget cutting. This persists despite earlier reform efforts. These earlier efforts have attempted to force the budget cutters to consider the impacts their cuts have upon activities or programs. Such a demand has greatly complicated the task of the budget cutters and made them resistant to reforms. ${ }^{47}$ Wildarsky notes that precise cutting of specific programs demands far greater knowledge than the budget cutters usually have. ${ }^{48}$ Further, it demands that the budget cutters be explicit about the activities or programs which will not be funded. The possibility of simply eliminating a small percentage of total budget from many programs (a meat-axe approach) is precluded. Reformers assume that analyses have a high degree of precision, perhaps higher than can be provided. In short,

45/bid., pp. 172-173.

46 Wildarsky, op. cit., pp. 165-167.

47 Schick, op. cit., pp. 173.177.

48 Wildavsky, op. cit., p. 148. 
the tasks of budget cutters are complicated by performance budget or PPB type reforms.

The legislative branch can be considered somewhat similar to other budget cutters. Certainly it plays a cutting role and is benefitted in the same way by traditional techniques. Further, however, the traditional techniques provide the line-items which are important simplifying devices to many legislators. As generalists (with the exception of certain committee members) the legislators would have little basis for detailed consideration of fundamental program changes. Complexities of programs are frequently so great that no legislator can thoroughly understand all aspects of the process by which a particular activity leads to an accepted objective. Simplifying devices are important. Looking at and questioning sharp growth in personnel costs or in travel expenses can afford the legislator an opportunity to elicit responses from agency representatives and to probe more deeply if necessary. It might seem ideal for a legislator to vote directly upon the implementation of a major new treatment modality at a state institution, but his or her understanding of the implications of that change would be sharply limited. Little would be gained over noting the associated increase in personnel expenses and, perhaps, compelling the agency to absorb some of these increases through attrition in other activities.

With all of these factors operating against earlier reforms, performance budgeting and PPB, it is not erribly surprising that neither was widely accepted despite partial implementation by many governmental units. ${ }^{49}$ But what of ZBB? Is there reason to expect its acceptance?

\section{Zero-Base Budgeting in Washington}

To this point most references have been to ZBB systems that have been in place for several years. It is appropriate, though, that a few com. ments be made on the federal government's ZBB system, presently being implemented.

Most important, the federal system varies little from that of Georgia. In a memorandum dated February 14, 1977, President Carter stated that, "A zero-base budgeting system permits a detailed analysis and justification of budget requests by an evaluation of the importance of each operation performed." He instructed the Director of the Office of Management and Budget $(O M B)$ to issue revised procedures incorporating ZBB techniques.

Under federal ZBB (as under other systems), agencies are required to specify decision units - "the program or organizational entity for which

4.9 Schick concludes that these political factors seem to have produced less resistance to PPB than to performance budgeting. 
a manager makes significant decisions on the amount of spending and the scope or quality of work to be performed. "\#) For each of these decision units there is a set of decision packages, each of which is a "brief justification document that includes the information necessary for managers to make judgments on program or activity levels and resource requirements. ${ }^{\prime \pi 1}$

Application of these features can be shown by a couple of examples. Guidance distributed within the Department of Housing and Urban Development listed sixty-one decision units including "payments for operation of low income housing projects." "urban renewal grants," "community development grants," and "housing counseling assistance." Some of these are consolidations of other, lower level, decision units. Following OMB guidance, it is required that there be for each unit a minimum level decision package - a request for the minimum amount of funds, for support at a level below which it would not be feasible or practical to continue the program or activity. Second, there is to be a current level package, indicating funds needed to continue the present level of activity through the budget year; it is recognized that such continuance might require more funds than provided at present. Finally there can be an improved level package, indicating the manager's recommended level of activity and associated costs.

These packages are supported by brief justification statements - and it is required that they be brief, normally limited to two pages. ${ }^{52}$ Statements of goals and objectives (as shown in instructional examples of $O M B$ and several agencies) are quite general. In Bulletin 77-9, OMB provided the following example for a community mental health grant program.

Goal: To ensure needy citizens access to community based mental health services, regardless of ability to pay. Services should be of high quality, provided in the least restrictive environment, and in a manner assuring patients' rights and dignity.

Objective: To assist in the establishment and operation of a nationwide network of 1,200 qualified community mental health centers (CMHCs) by 1984 to ensure availability and accessibility of services to residents of each mental health catchment area.

In its instructions, HUD used the following example:

Goal: Provide decent housing.

Objective: Over the next five years approve grants for construction of 70,000 units of multi-family housing in 30-units and 40-unit structures.

50Office of Management and Budget, Bulletin No. 77-9, April 19, 1977, p. 1.

51 lbid., p. 1.

52 Joel Havemann, "Zero-Base Budgeting," 9 National Journal (April 2, 1977), p. 517. 
As in Georgia, little emphasis is placed on systematic evaluation of program contributions to any goals or objectives that are more general than those most obviously associated with the program. Also as in Georgia, instructions place little emphasis upon seriously considering program or activity elimination. Such might happen as a result of the ranking process. but the possibility does not receive major attention..$^{53}$

\section{Conclusion}

If the description of ZBB presented above is accurate and if what is occurring is an effort to institutionalize a combination of performance budgeting and alternative budgeting, there is ample reason to question whether ZBB will be widely accepted (in more than in name) and will have any truly marked impact upon the budgetary process. There may be, however, some features about public attitudes today which could facilitate implementation. We have witnessed the election of a Presidential candidate who campaigned as an outsider to Washington and as a strong supporter of ZBB. While it is doubtful that his specific support for ZBB contributed greatly to his victory, his more general criticism of "Washington bureaucrats" may have helped. especially in the primaries. There may exist a reservoir of public support for a concerted effort to reduce government programs and employment and, hence, to support a budgetary scheme which purports to facilitate that. On the other hand, economic considerations will probably prevent sharp curtailment of either government spending or employment. Any results from immediate implementation of a ZBB system would need to be demonstrated through the transferring of resources among activities. Such results would be difficult to communicate to the public, and support for ZBB might be short lived.

If there may be support from the public, it is doubtful that much support will be found among participants in the budgetary process. The memory of PPB is still fresh and many agencies have continued to improve upon their cost/benefit studies and program evaluations. Of course, the federal budget process already includes activity measurements. What can be added would be the formal presentation of alternatives in the form of decision packages. Unlike Georgia, many federal agencies have available fairly adequate data bases for creation of supporting documentation. The particular forms employed would need to be far more elaborate than those used in Georgia to take advantage of such data. The complexity imposed upon reviewers would be many times larger.

53See this author's letter and Peter Pyhrr's response in 37 Public Administration Review (July/August, 1977), pp. 438-439. See also Donald F. Haider, "Zero Base; Federal State," 37 Public Administration Review (July/August, 1977), pp. 400-407. 
On the legislative side, Congress is still implementing its own new budgetary process. One must doubt that there will be much enthusiasm from members or staff for an extensive revision of executive budget procedures.

At the federal level, then, despite some possible support from the public, it seems doubtful that ZBB will make any real headway. The likely gain for various participants does not seem great enough to justify elimination of the traditional process and modification of the remnants of PPB to accord with the demands of ZBB.

In state and local governments a flurry of activity labeled "implementation of ZBB" continues. Although there is a general familiarity with the Georgia system, many of these governmental units may be devising their own procedures and, in fact, may be taking more literally the "justify from zero" prescription. For example, Oklahoma City, after examining the various attempts being made in Georgia and elsewhere, elected to simply instruct agencies to provide justifications from zero for twenty-five percent of their operations. Few additional instructions were supplied, although Budget Office staff members consulted with the agencies. What will result from such an unstructed process is difficult to determine. No doubt, there will be wide variation in the justification efforts. ${ }^{54}$

One fact is clear. The data problems encountered by Georgia are likely to be fairly common among state and local governments. It is significant that Georgia encountered problems even though the data requirements were quite minimal. Whether budget participants in state and local governments can justify the investment of time and money to meet even the level demanded by the Georgia system remains to be determined.

Zero-base budgeting, then, is something other than what the name implies, and probably less than what the name implies if the Georgia system is taken as the archetype. ZBB is an attempt to institutionalize a combination of older proposals for budget reform. This would be an accurate description, of course, even if actual justification from zero were required. Does this conclusion make the ZBB effort any less significant? Not necessarily, but it does place upon the proponents of ZBB a responsibility to demonstrate that (1) there have been political changes which now make institutionalization possible or (2) that the failure of earlier efforts resulted from improper approaches to institutionalization rather than from weaknesses inherent in the reform proposals themselves.

541 am indebted to the staff of the Oklahoma City Budget Office and its Director Joe Clytus for the use of their library and numerous conversations during the course of preparing this paper. 